\title{
Advanced Telecom Systems to Facilitate Collaborative Decision-making in Distributed Settings
}

\author{
Maria VISAN ${ }^{1}$, Firicel MONE ${ }^{1}$, Florin Gheorghe FILIP ${ }^{2}$ \\ ${ }^{1}$ Department of Engineering, Mechanics, Computers \\ Romanian Academy, School of Advanced Studies of the Romanian Academy, \\ 125 Calea Victoriei, Bucharest, \\ 2 The Romanian Academy, 125 Calea Victoriei, Bucharest, Romania \\ maria.visan@ingr.ro,mone@acad.ro, filip@acad.ro
}

The paper presents several practical issues concerning the multi-participant decision-making processes with emphasis on the crowdsourcing approach. The development of effective modern telecom systems that enable effective operations of multi-participant decision units are detailed. System scalability and operator's agility to incorporate continuous changing technologies challenge further research.

Keywords: Business Intelligence, Collaborative activities, Communication Infrastructure, Data Science, Decision Support System, Crowdsourcing

DOI: $10.24818 /$ issn14531305/25.1.2021.01

\section{1} Introduction

The developments of the present business models in the industry and public sector have led to evolutions and new characteristic features of decision-making activities [1] such as:

- More and more people with various types of expertise take part in decision-making activities. This feature requires an intensive exchange of information and collaboration to solve decision problems.

- Decision problems have become even more complex, multi-facet ones, characterized by plenty of unknown factors and, in a significant number of cases, required real-time solutions. The current pandemic phenomenon amplifies the complexity and novelty of the situation and, at the same time, makes even more critical the need for real-time decisions.

- To use the huge amounts of generated, transferred and accumulated data sets, Big data and Analytics have got ground in decision-making [2]. A rather recent document of World Economic Forum [3] describes a number of the world's most advanced enterprises, called lighthouses that largely make use of advanced technologies of the Fourth Industrial Revolution (FIR). It highlights the importance of data-driven decisions:" Big data decisionmaking is a value driver for impact at scale, one of the differentiators that transform how technology is implemented, how people interact with technology, and how it affects business decisions [...]. Decisions are not hypothesis-driven, but rather, based on big data deciphered by pattern recognition - and not by humans."

Shi [4] defines Data science as the methodology and practice of "data collection, management, transformation, analysis, and application, and its core is to study the acquisition of knowledge from data." The same author notices "Data science has begun to gradually replace the known business intelligence and business analysis in applications."

One can easily notice that there are a real need and a definite market for advanced and evolving computer-based tools to support collaborative /multi-participant data-driven decisionmaking activities. Besides AmI (Ambient Intelligence) [5] and IoT (Internet of things), such activities require in the case of geographically dispersed organizations, an increased level of data and information collecting and exchanging capacity. Adaptation to the new situation becomes new called for consequently and quickly telecom companies transformation. In the context briefly described 
above, the paper aims at presenting the envisaged evolutions in the telecom sector to cope with the challenges of the new requirements they face to enable effective crowdsourcing projects. The organization of the article sections is as follows: the next section sets the stage by reviewing several concepts related to multi-participant decision-making processes with emphasis on the crowdsourcing approach and platforms. The detailed description of the context, practical evolutions, and expectations in the telecom sector are included in the next sections together with their impact on multiparticipant decision-making activities. The fifth section reviewed several open problems.

\section{Multi-Participant Decision-Making}

\subsection{The Model}

In [6], the following definition of the decision was proposed: "The decision is the output of human conscious activities of choosing a feasible course of action (sometimes called alternative) with the view to attain a certain objective (or set of several, sometimes conflicting, objectives). It is followed by allocating the necessary resources. The decision is made by a decision unit that consists of a person (the decision-maker) or group of persons (the decision group) who are empowered to make the choice and are accountable for the quality of the solution adopted when approaching a particular problem."

The Nobel Prize laureate Herbert Simon defined the well-known process model of decision-making activities. The original model [6] consists of the following three phases:

- Intelligence, which consists of activities such as a) setting the objectives, b) data collection and analysis to recognize a decision problem, c) problem statement.

- Design, which includes activities such as a) identification (or designing) possible courses of action (alternatives), b) model building and c) evaluation of various potential feasible solutions to the given problem.

- Choice, or selection of a feasible alternative, called the decision, intending to release it for implementation.
- Later, Simon [7] introduced a fourth step that consists of the implementation of the solution and review of the results.

- In the case of a multi-participant setting, when the decision unit consists of several people, Konaté et al [8] propose an adapted model with the following phases:

- The preparation phase meant for defining the problem characteristic features such as the purpose, domain, current context, criteria, and possible constraints.

- Collective understanding of the problem is a continuation of the preparation phase and includes activities such as: sharing a common vision of the problem with all the participants and agreeing on how to implement the designed process;

- The solution generation phase is meant to let the participants produce individual ideas meant to solve the given problem.

- The confrontation of viewpoints and negotiation is the phase in which the individual decision-makers that have elaborated their contributions present them intending to win the acceptance and support of the other participants.

- The decision phase consists of selecting, according to the criteria previously collectively defined, the ideas which have been accepted by most of the participants or which will possibly lead to reaching the consensus within the group;

- The monitoring phase covers all phases of the decision-making process so that in the allocated period the problems are solved. It includes generating a report on all decision-making activities and ensures the implementation of the adopted solution.

Concerning the number of participants, there are several subclasses of decision units that can be composed of a) one person, helped or not by a team of experts, b) a group of a limited number of people possessing equal decision powers (peers), or placed on various levels of influence (organizational groups), c) a very large number of persons (the crowd).

Other characteristic attributes of the decision units are a) the place of work: the same place or different places (remote work), b) the moment of interaction: synchronous (same time) 
or asynchronous (different time), c) type of interaction: direct (face-to-face) or indirect and mediated by the communication technology. It is the last class of decision units that is of interest in the context of the paper. Of equal interest is the class composed of two sub-classes of people namely: a) the decision-makers, and b) the beneficiary/affected persons or communities influenced by the release and implementation of the adopted decision.

\subsection{Crowdsourcing Concept and Platforms} Decision Support Systems (DSS) [9], [10], [11] are information systems meant to help the human to solve complicated decision problems. If the decision unit is composed of several persons, a Group DSS may help. In a multi-participant decision-making setting, one central problem is attaining consensus by aggregating individual preferences and improving decision matrix consistency. A great number of multi-criteria models [12] and consensus-reaching methods [13], [14], [15] have been proposed and documented in the literature even for large numbers of participants. A second important aspect of multi-participant decision-making is ensuring effective and secure communication among participants. This second aspect is addressed later in the paper. There are, however, situations when the decision problems are too difficult and cannot be solved by the decision-maker and his close collaborators or hired external consultants. To overcome the situation, the decision-maker could resort to crowdsourcing in the hope that the created crowd wisdom would help to get at the feasible solution [16]. Estellés-Arolas and Gonzales-Ladron-de Guevara [17] define crowdsourcing as "a type of participative online activity in which an individual, an institution, a non-profit organization or a company proposes to a group of individuals of varying knowledge, heterogeneity and number, via flexible open call, the voluntary undertaking a task. The undertaking of the task, of variable complexity and modularity, and in which the crowd should participate bringing their work, money, knowledge, and experience, always entails mutual benefit."

Collaboration aspects in crowdsourcing were studied [18] and profit maximization solutions were proposed [19]. There are available crowdsourcing practical platforms such as Amazon's Mechanical Turk3, and CrowdFlower; Microworker; mCrowd, Climate CoLab, InnoCentive, Spigit, and Brightidea and so on [20], [21]. Ciurea and Filip [22] provide a comparative analysis of several platforms.

It is worth noticing that crowdsourcing is not, however, the silver bullet for any difficult problem. There have been identified a series of limitations of the crowdsourcing approach [21]. Several such limitations are a) a possible "herding" behavior as a consequence of the serial contributions and up-voting enabled by platforms, b) the lack of the required expertise not possessed by the majority of the crowd members, c) the big data aspect, namely the huge effort needed for processing an enormous number of individual contributions could create problems that can, paradoxically, make the decision-takers to focus on a limited number of familiar ways of action and ignore the novel approaches and so on. What is uncertain is the fact that activities of many multiparticipant decision units (groups of remote peers, organizational groups or crowds) require effective communication means.

The larger the number of participants is, the higher requirements are for the data volume and quality of communication means.

In the evolution of the last decades, each stage has brought a series of transformations that more or less have disrupted the industries. As a vector of development, in the past and today, the telecom industry has been considered at the forefront of change and has undergone huge changes due to life events digitalization. Because of the emergence of social media platforms, new possibilities opened up for connecting people. Innovative digital devices and over-the-top (OTT) applications change the traditional telecommunications business and the process continues. Although the digital experience, cloud and analytics do not finalize their journey for telecom operators, emergence trends like IoT combined with cognitive technologies - augmented or virtual 
reality, machine learning, robotic process automation, natural language processing, neural networks or artificial intelligence become a driving factor enhancing the business and civil society environment and customer habits, as Deloitte experts mentioned [23]. Covid -19 crises become a driver for innovations and many changes affected already the customer behaviour and also business and operational [24]

Whether the topics related to the business digitalization and life cycle of the infrastructure optimization are old, the pandemic related to technological trends put pressure on telecom operators asking for: upgrading existing tools, increasing organizational agility and creating the engine for managing data with analytics into an integrated collaborative environment for decision-making. Experts [25] suggest that the digitization process represents the transition to another level of maturity for operators, which opens up the Internet of Things (IoT) for optimizing their activities, but also for offering value-added services.

Due to the large volumes of data and the evolution of consumer habits, traditional solutions can no longer meet these challenges and more important not all the activities are initiated and completed at the level of a single organization. Most of the time in this connected world, decision-making is no longer only at the departmental level, but also between different departments and sometimes request multi-institutional level. Thus, the big data and data analytics solutions implemented that allows collaboration on groups and multi-participant decision-making are the best choice.

\section{Historical Telecom Operators' Problems Require Big Data and Analytics in a Multi- Participant Decision-Making Environment}

The problems faced by telecom operators, their possible solutions and the impact relevant for the new value-added services [26], [27] are amplified by economic pressures or continuously changes in consumer habits, all happened today in a shorter time than natural. Adding external information from social media or demographics, or other information provided by marketing researchers the tech forces provided analyses and prediction tools for business collaborative decision- making. The digitalization process in line with technological trends capture the attention of telecom managers and activate the new business models, unexploited yet.

The main internal processes that add value and contribute directly to the digitalization of a telecom operator are network infrastructure, services and security, marketing and sales. Each of these involves a mixed decision support system group: a limited number of persons from the operator's internal departments (network asset management, network quality, performance and network optimization, network planning, call centre, field crew, IT, etc.), a group of a limited number of customers affected by the problem, and the crowds (potential customers, young generation, people with the most expertise, unexpected sources etc.) capable to develop more diverse ideas. For defining the new business proposals and select the final decision, operators involve a multi-participant decision-making environment and integrate a huge amount of data formats (structured and unstructured) and their cross-referencing analysis (call centre call packets and customer wear, customer experience related to network congestion).

A. Network Infrastructure Management. Indepth analysis of financial indicators such as CAPEX (Capital Expenditure) and OPEX (Operating Expenditure) and use of Big Data analyses that determines the most negative customer experiences, the improvement of business decisions regarding network infrastructure [28], [29] including interactively real-time network analyses, both for emergency response and for long-term planning such as capacity planning, network modernization/upgrading, performance management, performance and network optimization. For example, the internal data collected from different user types of equipment could be used also for developing new services (traffic flows based on the GPS position of mobile equipment, population densities in certain areas, lo- 
cation and routes, etc.). For externalized services of the field crew, when the equipment is installed on buildings, the team access requires coordination with the construction administrator and require a collaborative environment. As lower bandwidth is the main factor that influences the quality of service for customer's mobile applications, based on contracted Service Level Agreements (SLA) [31] and virtualized resources operators allocate more bandwidth in real-time or they could also suppress services or devices to answer to specified intervention time. Using cognitive technologies operator can predict traffic problems and interpret the requirement for realtime bandwidth allocation, at the same time generating alarms. For each internal network infrastructure management processes, the big data solution affects many areas, such as network performance, revenue streams and customer experience and activates the new business models, unexploited yet (providing advice to retailers to support local store bidders and determine the best locations and formats for new stores, joint promotional proposals and ticket packages to increased sales, optimizing routes and service quality by analysing network traffic in real-time).

B. Service access integration and security. More data available allowing better analyses for better operational decision-making with the condition to collect and store intelligent data records. Focusing on improving customer experience combined with localization and other external data (for example, social media), gives the operator options for fraud prevention, generating new services and more valuable functionalities for customer interactions. At the same time operator can develop new customer experiences keeping at the same time the data protection and security for user's devices. All these efforts not just provide better financial management and improving the total cost of services, but also prevent and detect more easily fraud and most important customer retention. Crowdsourcing for better understanding customers could generate a new perspective that can increase rev- enue, reduce costs by customizing and correcting issues before the customer in every field of activities perceives them negatively. C. Marketing and Sales. Big data solutions promote marketing and sales using methods such as 360-degree view of customer value, smart/personalized marketing campaigns, anticipating customer needs upselling and crossselling, NPTB recommendations, churn reduction. Personalized campaigns that use location-based information, combined with social media and other data sources such as call debt, demographics and so on and predictive modelling can offer products and services that correspond to customer needs and lifestyle. Discounted personalized offers for upgrade also prevent customer loss. Combining real-time location information with historical data for intelligent marketing (personalized marketing campaigns or sending promotional messages to exactly the right customer), that are in the right place and time. By doing partnerships with other private or public organizations, the conversion rates for marketing campaigns as well as sell them to merchants for third-party ads targeted to the right segment at the right time in the right place. These types of personalized marketing promotions prevent customer loss, increase sales, and reducing marketing campaign costs. Examining user behaviour helps to understand how to better deliver media content and thus influence customer experiences and anticipating the wishes and customer needs in a sales situation or to provide services known as "best action" require the management and individualization of recent customer interactions taking into account the collaborative environment with sales and service channels and require the best new or update the existing services. Big data and prediction modelling tools could be used to implement customer satisfaction metrics. The impact of the proposed solution increases revenue and profit, predict sales potential.

\section{Telecom System Evolution}

The evolution of telecom industries, the market repositioning of other players with new value-added services that generating losing 
telecom customers and revenue and the request for diversification of services is an imperative requirement in the digital transformation era. Today, more and more telecom activities are outsourced and involve the collaborative multi-participant decision-making environment. Pandemic brings other challenges: teleworking activities in a collaborative environment, more bandwidth for supporting the business activities, applications and security. The challenges become bigger when part of the business is performed together with third parties and requires, in the context of changing the way of working, decision-making in the multi-participant environment or collaboration groups.

Figure 1 depicts the collaborative multi-participant decision-making environment, the levels of digital maturity and operational workflows that involve common reality (based on real-time or historical data, workflows for each component that contribute directly to the digital transformation processes for the telecom operators.

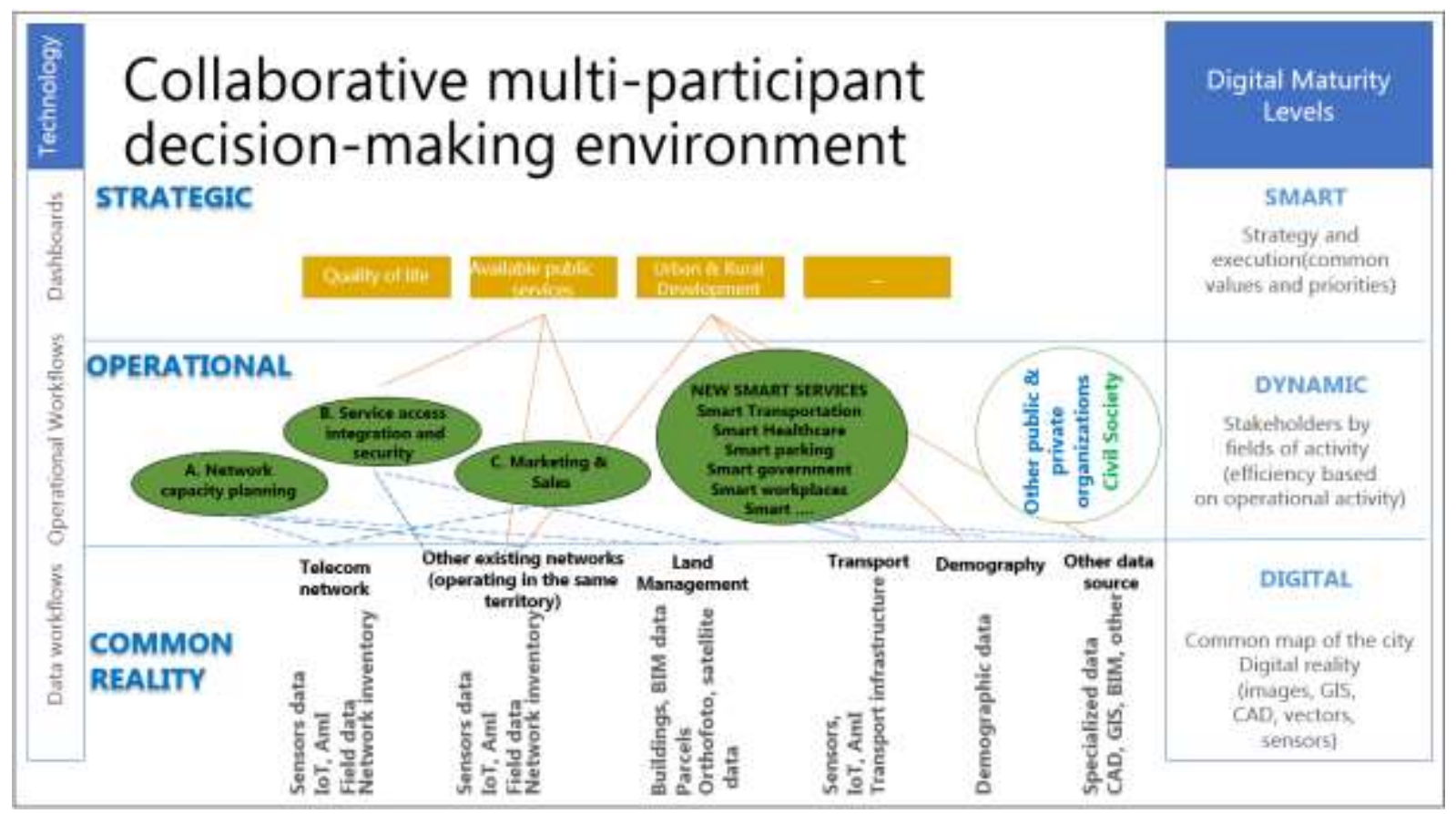

Fig. 1. Collaborative multi-participant decision-making environment for a telecom operator

The influence of a telecom operator could be extended within the digital ecosystem based on alliances with other complementary business entities. Some crowdsourcing platforms are related to value-added services previously presented or newly developed in the future. Testing the new value-added services before officially launching on the market could be done by public or small groups, or by dedicated companies that are willing to participate as crowds. The result is not only services testing, but also incorporating market feedback, before launching the service. Crowdsourcing gives answers related to services and information about what customers want. This builds a community where customers vote for the best services/features. Advanced analysis tools allow the extraction and understanding of recurring problems and proposals, publishing relevant content for refining proposals. Alternatively, another category of use could be the use of experience with outsourced resources, for example, provide in-house technical support, interacting with a customer via social media using their daily webchat, on the favourite platform.

Mobile crowdsourcing technology highlights several possible projects in the following categories [34]: 1/Cooperative traffic - for example, Google Maps and Waze already using the mobile GPS positioning for traffic manage- 
ment and public information [35]; 2/Geo-social networking - for example, Google Latitude and Loopt generate social networks that support the geospatial location and Twitter incorporates the best practices for real-time streaming [36];3/Product testing - activities realized by dedicated companies, for example, uTest or Mob4Hire use crowds to test newly developed mobile applications and provide feedback on functionalities, such as load, performance, and usability [37];4/User Content Generation - are mobile application services for video sharing such as Qik and Kyte based on crowdsourcing that generates a wide variety of content similar to YouTube [38];5/User experience optimization - similar to Google, information providers integrates and analyses mobile data extracted from the crowd for helping optimizing user experience [39];6/Leveraging mass reach - creating content mobile platforms [40].

Figure 2 define the participant's type in the Group Decision Support System based on the operator's internal departments, customers (affected by the problem) and the crowds (experts, next generations, others willing to provide innovative ideas) willing to participate in the collaborative multi-participant decisionmaking processes for defining new smart services.

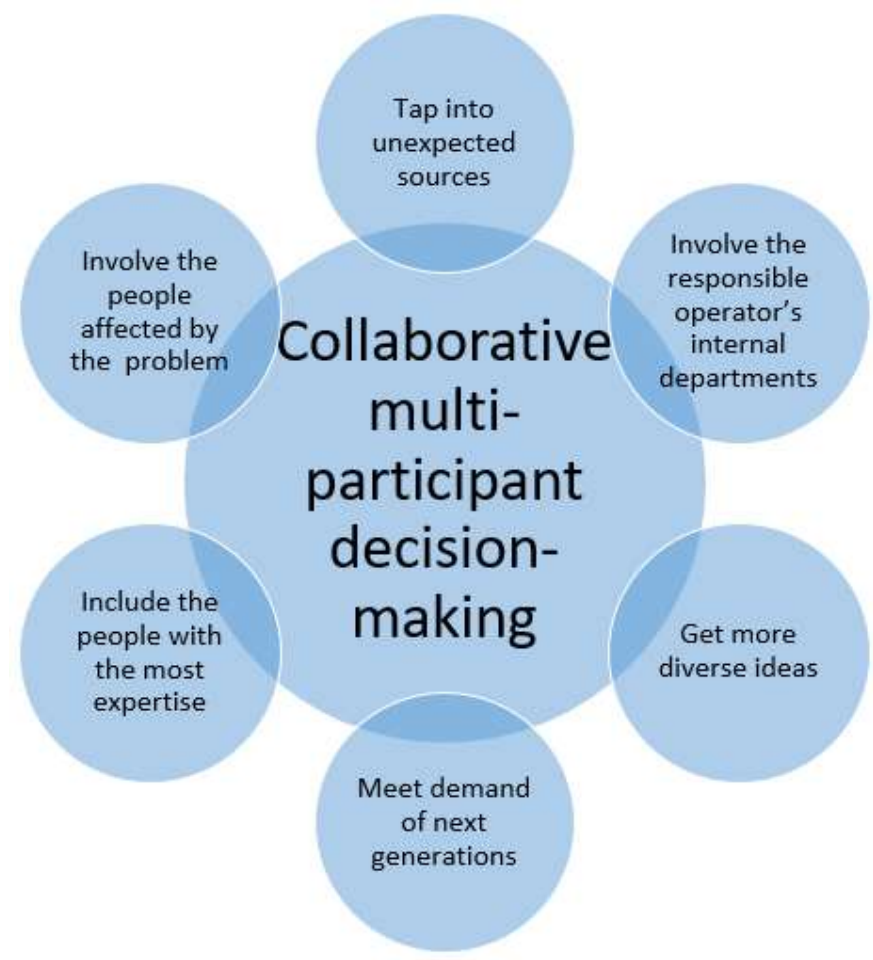

Fig. 2. Group Decision Support System

Source: adapted after [22]

The digital transformation is a road that changes several internal activities step by step. The first step is transforming the perspectives on data: correlate data about products and services, with customer data. As a result, they lacked the data collection and organization strategy. This digital transformation cannot be achieved overnight due to the significant investment in software and hardware data infrastructure. The entire architecture must be de- signed to be subordinated to the Big Data strategy capable of generating sustainable value and meet business requirements. Valorisation, correlation, integration and timely transformation of relevant data into actionable information are realized using analysis, analytical and reporting tools for relevant performance indicators and customer experience management, dashboard controls for decision-making and alerts that interpret the requirements in 
real-time. Shortening the life cycle loop of information from data acquisition to action, adding analysis engine (descriptive analytics what happened, diagnostic analytics - why something happened, predictive analytics what is going to happen, prescriptive analytics - recommending actions, automated analyticstaking actions automatically), support decision-making in a shorter time and allowed proactive actions to be taken. Mechanisms of analysis on structured, unstructured or mixed data type in real-time or almost real-time from voice to text, natural language text analysis (NLT) taken from the call centre, conversation transcription, or more recently, the use of artificial intelligence, machine learning and analytics for the voice and video recognition and interpretation, sentiment analysis for extracting nuances of language, feelings, intentions and much more related to user experiences, social media analysis, changing the business model. For historical data collected over the years, capitalized in data lakes scalability is a recommended feature and has to be expanded to handle ever-increasing volumes of data. The final step, analysis and intelligent autonomy suppose the existence of systems that are aware of the events that occur in real-time and that can provide information for solutions with immediate execution. For example, automatic contextual notifications e.g. "free meal offered or discounted cake" received in real-time when asked a question about the location of a restaurant. As contextual information in the "Internet of everything" and data on social platforms become increasingly important to support decision-making, operators should focus on automating prescriptive analysis.

\section{Open Problems}

If the digital transformation has not started either through individual activities or based on alliances with other complementary business entities, a big question is how the telecommunications sector will transform and ingest the technological change: $5 \mathrm{G}$, artificial intelligence, augmented reality autonomous and so on in the context of activities that are almost extinct today? This challenge affected all dis- ciplines and in all their dimensions and telecom companies plays a major role in the "applications and design" of "intelligent systems".

The operators ready to adopt AmI technology will ensure a reduction in downtime for their networks. The operators that offer Internet services will play a major role in the implementation of AmI in the market for other companies or citizens and generating smart services (Smart government, Smart Healthcare, Smart transportation, Smart Parking, Smart environment, Smart agriculture etc.). The huge amount of data provided via AmI, make data available immediately, without human intervention, and generate a request for immediately operationalize these data in a collaborative multi-participant decision-making environment. Today Artificial Intelligence (AI) through assistants and robots improve customer relationship, network optimization and maintenance, detecting fraud adding business information or based on predictive analytics. If a decade ago, there were only warnings that only a few smart companies will increase their revenues and develop their market position based on intensive and immersive AI intervention in various fields, telecom being considered a driver, today the intelligent edge helping the fourth industrial revolution by bringing the power of computing closer to where the data are generated, increasing the efficiency of the operation [44]. The 2021 spending for telecom services has a $6 \%$ growth compared with the previous year (1,4 trillion USD dollars) [45]. Sectors such as virtual travel, shopping, entertainment, distance assistance, teaching and training are touched by this huge transformation that reaches virtually all other industries. For example, the medical industry is expected to benefit immensely from the growth of these technologies - telemedicine, the machine learning compatible microscope is already equipped to find cancer cells in tissues. Even in the gambling industry, consumers face more difficult video games with active AI virtual opponents. In social interactions, VR (Virtual Reality) and AR (Augmented Reality) will provide more collaboration platforms, especially with distance learning and meetings. VR 
/ AR in tourism will also allow users to experience tourist destinations, whether it is a hotel room or an adventure sport, before stepping out of the comfort of their own homes.

Collecting Big Data from mobile devices to their advantage, adopting smartphone applications, new technologies and much more, the main players in the telecom market will become prosperous generating new opportunities for partnerships in which the combination of technological vectors will be unprecedented, even if today are considered open problems.

\section{Conclusions}

Compared to other industries, telecommunications lead in terms of the amount of data they manage and based on their major impact in other industries. The operators become a driver of development. Besides, the wealth of information naturally available to operators, and due to their accessibility can be a solution to the challenges currently facing telecommunications operators. By solving those using Big Data, algorithms and especially by sharing decisions making in group collaboration and multi-user decision-making with partners in a multi-institutional framework, each user interaction is enriched and innovative experience is obtained. Setting up digital business associations will focus exclusively on creating valueadded digital services. If at the beginning of the implementation of these solutions the basic activity will cover the internal operational activities, later they provide the basis for the development of new dimensions by integrating the data, developing the business of each participant in the partnership. For example, by combining the entertainment industry with the telecommunications one, Netflix and Spotify are an eloquent example of a partnership that generates competitive advantages for telecom operators, and collaboration packages that result from a flow of new customers.

Other operators have chosen to expand their core business by generating services that address the business environment, as Verizon has done through Verizon Enterprise Solutions (Laurie Spiegel 2018), providing support for managing multi-user day-to-day activities, teams and decisions, using cloud technologies.
By associating with Google Apps for business data derived from user analysis, services extensions were generated using dedicated communication systems, such as a simultaneous call with multiple options (office, mobile and personal lines), visual messages through voice mail, and the adoption of the "office anywhere" business model, increasing the team productivity and the development of services addressed to customers. To meet customers, partners with whom they collaborate, employees can decide, for example, how to be called and on what type of device (phone, landline or mobile). With industry-specific solutions and a full range of global offerings through enterprise mobility, cloud, strategic networking and advanced communications platforms, Verizon Enterprise Solutions provides support for new investments and innovative digital transformations.

We have expected a huge impact of pandemic against smart services developed by telecom operators in partnerships with other public or private organizations and civil societies (economic agent, citizens) and the development of multi-participant decision-making, collaborative and crowdsourcing business models.

Adopting a Big Data strategy and strategic planning, framing all actions in an integrated and continuous model of digital transformation, oriented on the embrace of new technologies, with openness to deal with disruptions that manifest themselves continuously, with good institutional agility, it will be not only reducing the costs and contributes to better management of customer relationship but for telecom operators, it also contributes to strengthening customer loyalty, maintaining and developing the market leader position. Although it seems that everything happens at the level of an individual operator or of the telecom industry level, the continuous changes of technological games affect not only the telecom industry but the entire global economy.

\section{References}

[1] F.G. Filip, C.B. Zamfirescu, C. Ciurea, (2017), "Computer-Supported Collaborative Decision-making”, Springer, Cham. 
[2] Y. Shi, P. Quan, (2020), "Big Data Analysis: Theory and Applications", Lirkov I., Margenov S. (eds) Large-Scale Scientific Computing. LSSC 2019. Lecture Notes in Computer Science, vol 11958. Springer, Cham.

[3] WEF, (2019), "Fourth Industrial Revolution Beacons of Technology and Innovation in Manufacturing". World Economic Forum.

[4] Y. Shi, (2018), "Big Data analysis and the Belt and Road initiative". The 2018 Corporation Forum on "One-Belt and OneRoad Digital Economy", September 21, 2018, Chengdu, China.

[5] M. Khakifirooz, M. Fathi, Y.Ampatzidis, P.M. Pardalos, (2020), “Ambient-Intelligent Decision Support System (Am-IDSS) for Smart Manufacturing", Encyclopedia of Organizational Knowledge, Administration, and Technology, p14, DOI: 10.4018/978-1-7998-3473-1.ch161,

[online] Available: https://www.igiglobal.com/chapter/ambient-intelligentdecision-support-system-am-idss-forsmart-manufacturing/263695 (Accessed 28.03.2021).

[6] F.G. Filip, (2008), "Decision support and control for large-scale complex systems". Annual Reviews in Control 32(1):61-70.

[7] H. Simon, (1960/1977), "The New Science of Management Decisions", Harper\&Row, New York (revised edition in Prentice Hall, Englewood Cliffs, N.J., 1977).

[8] J. Konaté, P. Zaraté, A. Gueye, G. Camilleri, (2020), "An ontology for collaborative decision-making. Morais D, Fang L, Horita M. (eds) Group Decision and Negotiation: A Multidisciplinary Perspective". GDN 2020. Lecture Notes in Business Information Processing, vol 388. Springer, Cham, pp. 179-191.

[9] F.G. Filip, K. Leiviskä, (2009), "LargeScale Complex Systems". Nof S. (eds) Springer Handbook of Automation. Springer Handbooks. Springer, Berlin, Heidelberg.

[10] A. Kaklauskas, (2015), "Biometric and intelligent decision-making support".
Springer, Cham, Heidelberg, Intelligent Systems Reference Library book series (ISRL, volume 81).

[11] D.J. Power, C. Heavin, P. Keenan, (2019), "Decision systems redux", Journal of Decision Systems, [online] Available: https://doi.org/10.1080/12460125.2019.1 631683 (Accessed 28.03.2021).

[12] EK. Zavadskas, J. Antucheviciene, P. Chatterjee, (2019), "Multiple-Criteria Decision-Making (MCDM) Techniques for Business Processes Information Management". Information10(4).

[13] E. Herrera-Viedma, F. Herrera, F. Chiclana, (2002), "A consensus model for multiperson decision making with different preference structures", IEEE Transactions on Systems, Man, and CyberneticsPart A: Systems and Humans, 32(3): 394402.

[14] G. Kou, D. Ergu, J. Shang, (2014), "Enhancing data consistency in decision matrix: adapting Hadamard model to mitigate judgment contradiction", 236 (1): 261271, European Journal of Operational Research 236(1):261-271, [online] Available:

http://dx.doi.org/10.1016/j.ejor.2013.11.0 35 (Accessed 28.03.2021).

[15] C. Lin, G. Kou, Y. Peng, F.E. Alsaadi, (2020), "Aggregation of the nearest consistency matrices with the acceptable consensus in AHP-GDM". Annals of Operations Research [online] Available: https://doi.org/10.1007/s10479-02003572-1 (Accessed 28.03.2021).

[16] F.G. Filip, (2020), "DSS - a class of evolving information systems". In Dzemyda G., Bernatavičienè J., Kacprzyk J. (eds) Data Science: New Issues, Challenges and Applications. Studies in Computational Intelligence, vol 869. Springer, Cham.

[17] E. Estellés-Arolas, F. Gonzales-Ladronde-Guevara, (2012), "Towards an integrated crowdsourcing definition". J Inf Sci 38(2):189-200.

[18] H.J. Khasraghi, R. Hirschheim, (2021), "Collaboration in crowdsourcing contests: 
how different levels of collaboration affect team performance", Behaviour \& Information Technology, [online] Available:

https://doi.org/10.1080/0144929X.2021.1 8 (Accessed 28.03.2021).

[19] Q. Li, L. Lijun Cai, H. Xu, T. Meng, (2021), "Profit maximization in mobile crowdsourcing: a competitive analysis". IEEE Access, 9: 27827-27839.

[20] Y. Wang, X. Jia et al, (2016), "Mobile crowdsourcing: framework, challenges, and solutions". [online] https://doi.org/10.1002/cpe.3789 (Accessed 28.03.2021).

[21] L. Metcalf, D.A. Askay, L.B. Rosenberg, (2019), "Keeping human in the loop; Artificial swarm intelligence to improve business decision making". California Management Review 61(4):84-109.

[22] C. Ciurea, F.G. Filip, (2019), "Collaborative platforms for crowdsourcing and consensus-based decisions in multi-participant environments". Informatica Economică 23(2): 5-14.

[23]

https://www2.deloitte.com/us/en/in-

[online] sights/industry/retail-distribution/the-consumer-is-changing.html

(Accessed 28.03.2021).

[24]

https://www2.deloitte.com/global/en/blog /responsible-business-blog/2020/covid19-drives-lasting-changes-in-global-consumer-behavior-and-businesses-operations.html (Accessed 28.03.2021).

[25] F. Grijpink, E. Kutcher, A. Ménard, et al., (2020), "Connected world. An evolution in connectivity beyond the $5 \mathrm{G}$ revolution. McKinsey Global Institute". [online] Available: https://www.mckinsey.com/industries/technology-media-and-telecommunications/our-insights/connectedworld-an-evolution-in-connectivity-beyond-the-5g-revolution

(Accessed 28.03.2021).

[26] M. Visan, F. Mone, (2018), "Big data services based on mobile data and their strategic importance", 7th International Conference on Computers Communications and Control (ICCCC 2018), Oradea, pp. 276-281, 2018.

[27] M., Visan, A. Ionita, F.G., Filip, (2020), "Data Analysis in Setting Action Plans of Telecom Operators", In Dzemyda G., Bernatavičienè J., Kacprzyk J. (eds) Data Science: New Issues, Challenges and Applications. Studies in Computational Intelligence, Springer, 869, pp. 97-110.

[28] R. Meakin, (2017), Telecom capital expenditure (Capex), Pwc, [online] Available: https://www.pwc.com/gx/en/industries/tmt/ telecommunications/capex.html (Accessed 28.03.2021).

[29] N. Clinckx, Y. Baffalio, (2014), "Optimize network OPEX and CAPEX while enhancing the quality of service", Telecom, media and technology, EYGM Limited. [online] https://www.ey.com/Publication/vwLUAssets/EY_Optimize_ network_OPEX_and_CAPEX_while_en-

hancing_the_quality_of_service/\$FILE/EY-optimize-networkOPEX-and-CAPEX.pdf (Accessed 28.03.2020)

[30] N. Miloslavskaya, A. Tolstoy, (2016), Big Data, Fast Data and Data Lake Concepts, Procedia Computer Science, Volume 88, 2016, pp. 300-30.

[31] C. Vemulapalli, S.K. Madria, M. Linderman, (2020), "Security Frameworks in Mobile Cloud Computing". In: Gupta B., Perez G., Agrawal D., Gupta D. (eds) Handbook of Computer Networks and Cyber Security. Springer, Cham. [online] Available: https://doi.org/10.1007/978-3030-22277-2_(Accessed 28.03.2020).

[32] B. Zhao, S. Zhang, J. Zheng, (2017), "Research on XDR Bill Compression Under Big Data Technology". In Zou B., Li M., Wang H., Song X., Xie W., Lu Z. (eds) Data Science. ICPCSEE 2017. Communications in Computer and Information Science, vol 727. Springer, Singapore. [online] Available: https://doi.org/10.1007/978-981-10-63855_13 (Accessed 28.03.2020).

[33] P. Patel, A.H. Ranabahu, A.P. Sheth, (2009), "Service Level Agreement in Cloud Computing". [online] Available: 
https://corescholar.libraries.wright.edu/knoesis/78 06.07.2020).

[34] N. Shadbolt, K. O'Hara, D. De Roure, W. Hall, (2019), "The Theory and Practice of Social Machines", Lecture Notes in Social Networks, Springer, 2019, ISBN 3030108899, 9783030108892.

[35] N. Alam, A.G. Dempster, (2013), "Cooperative Positioning for Vehicular Networks: Facts and Future", IEEE Transactions on Intelligent Transportation Systems, vol. 14, no. 4, pp.1708-1717.

[36] Y. Doytsher, B. Galon, Y. Kanza, (2010), "Querying geo-social data by bridging spatial networks and social networks", Proc. the 2nd ACM SIGSPATIAL International Workshop on Location-Based Social Networks, November 2010, pp3946 [online] Available: https://doi.org/10.1145/1867699.1867707 (Accessed 28.03.2020).

[37] S. Alyahya, (2020), "Crowdsourced Software Testing a Systematic Literature Review", 2020 Information and Software Technology.

[38] L. Gao, M. Tang, J. H. Pang, J. Huang, L. Sun, (2016), "Performance bound analysis for crowdsourced mobile video streaming”, 2016 Annual Conference on Information Science and Systems (CISS), Princeton, NJ, 2016, pp. 366-371.

[39] H. Wigelius, H. Väätäjä, (2009), “Dimensions of Context Affecting User Experience in Mobile Work", Gross T. et al. (eds) Human-Computer Interaction - INTERACT 2009. INTERACT 2009. Lecture Notes in Computer Science, vol 5727. Springer, Berlin, Heidelberg.
[40] V. Feldman, (2005), "Introduction. In: Leveraging Mobile Media. Information Age Economy", Physica-Verlag HD, [online] Available: https://doi.org/10.1007/3-7908-16337_1(Accessed 28.03.2020).

[41] A. Kaklauskas, (2015), "Biometric and intelligent decision-making support". Springer, Cham, Heidelberg

[42] "Technology, Media and telecommunication predictions 2021". [online] Available: https://www2.deloitte.com/content/dam/insights/articles/US93838_TMT_Predictions_2021/DI_2021-TMT-predictions.pdf (Accessed 28.03.2021).

[43] F. Mass, (2020), "Worldwide Spending on Telecommunications". [online] Available: https://www.idc.com/getdoc. jsp?ContainerId=prUS46222120 (Accessed 28.03.2021).

[44] S. O'Dea, (2021), Telecom services: global spending forecast 2008-2022, [online] Available: https://www.statista.com/statistics/203293/global-telecom-services-spending-forecast/\#: :text=In\%202021\%2C\%20telecommunication $\% 20$ services $\% 20$ spending,(COVID\%2D19)\%20pandemic (Accessed 28.03.2020).

[45] L. Spiegel, (2018), "How Verizon deploys virtual network services". [online] Available: https://www.forbes.com/sites/bernardmarr/2019/10/14/the-7-biggest-technology-trends-that-willtransform-telecomsin-2020/\#7d23fb286033 (Accessed 28.03.2020).

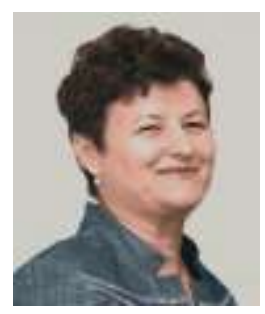

Maria VISAN has graduated from the Faculty of Automatic Control and Computers, Software Department at the Polytechnic University of Bucharest in 1992. Currently, she is PhDC, within the Department of Engineering, Mechanics, Computers, Romanian Academy, School of Advanced Studies of the Romanian Academy. Her main research interest includes Big Data, Data Analytics and Business Intelligence, location intelligence. 
Firicel MONE received his University degree - physicist 1999, University of Bucharest, Faculty of Physics. Currently, he is PhDC, within the Department of Engineering, Mechanics, Computers, Romanian Academy, School of Advanced Studies of the Romanian Academy. His research interest includes Collaborative Systems for Assisted Decision - Making.

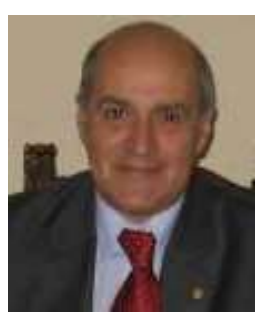

Florin Gheorghe FILIP received his MSc and $\mathrm{PhD}$ in control engineering from the "Politehnica" Techn. The University of Bucharest in 1970 and 1982, respectively. He was with the Institute for Informatics, Bucharest (19702015). In 1991, he was elected member of the Romanian Academy, whose vice-president he was elected in 2000 and re-elected in 2002, and 2006). His main scientific interests are hierarchical control and decision support systems. He (co)authored some 350 papers and 13 monographs and was the (co)editor of 30 volumes. 